\title{
Weight Loss Corrosion Study of Some Metals in Acid Medium
}

Aminu D. Usman, Adams F. Victoria, *Linus N. Okoro,

${ }^{1,2,3}$ Department of Petroleum Chemistry \& Engineering, School of Arts \& Sciences, American University of Nigeria, Yola, Adamawa State, Nigeria.

*Corresponding Author: linus.okoro@aun.edu.ng

\begin{abstract}
This research was undertaken to examine the corrosion behavior of some metals in different acid solutions using weight loss technique. The magnitude of corrosion of these metals in $0.5-3.0 \mathrm{M}$ of solutions of $\mathrm{HCl}, \mathrm{H}_{2} \mathrm{SO}_{4}$, and $\mathrm{HNO}_{3}$ was studied for an exposure period of 100 minutes (at 20 minutes interval). Rate of corrosion in metals followed this order: zinc $>$ galvanized iron > copper $>$, while rate of corrosion in aqueous media followed this order: $\mathrm{HNO}_{3}>\mathrm{H}_{2} \mathrm{SO}_{4}>\mathrm{HCl}$. It has been obtained that concentration increase leads to increase in rate of corrosion. Further study on the corrosion kinetics has revealed that the rate of reaction of the metals increases with increase in solution concentration, while the half life decreases with increase in solution concentration.
\end{abstract}

Keywords: Weight loss; acid; concentration; exposure time; rate of reaction.

\section{Academic Discipline and Sub-Disciplines}

Chemistry

\section{SUBJECT CLASSIFICATION}

Corrosion Chemistry

\section{TYPE (METHOD/APPROACH)}

Weight Loss Method, Corrosion Study

\section{Council for Innovative Research}

Peer Review Research Publishing System

Journal: Journal of Advances in Chemistry

Vol. 11, No. 2

editorjaconline@gmail.com

www.cirjac.com 


\section{INTRODUCTION}

Due to their wide applicability in both small and large scale industrial operations and processes, metals and metal alloys very often tend to come in contact with very aggressive solutions such as acids and bases [1]. As such, they are predisposed to corrosion attacks whose magnitudes depend on several factors like concentration of the solution or medium, time of exposure, and temperature conditions amongst others [1-3].

Corrosion which is derived from the Latin word "corrodere (meaning to eat away)" occurs when a given material (metal, ceramic, rubber, polymeric \& cement structures, etc) undergoes a chemical or electrochemical reaction with the surrounding environment, resulting in a gradual deterioration, destruction, or in extreme cases structural failure of the metal $[2,4,5,6]$. Corrosion is highly destructive and occurs in practically every given environment which includes the atmosphere, air and water mixture, industrial atmosphere (gases, alkali, acids, etc), fresh and salty water, and other organic and inorganic solutions or media [2, 4, 5, 6].

Corrosion occurs at a slow or fast pace, and the rate at which it occurs could be monitored using different techniques, the most common of which is weight loss method $[5,6]$. In this method, the specimen of a given material (known as the coupon) is exposed to a process environment for a given duration of time. This specimen is then removed for analysis which begins with measurement to determine the weight loss taking place over the period of exposure. This is then expressed as corrosion rate [7].

Weight loss method was utilized in this research to examine the corrosion behavior and mechanism of galvanized iron, zinc, and copper in different concentrations of solutions of $\mathrm{HCl}, \mathrm{HNO}_{3}$, and $\mathrm{H}_{2} \mathrm{SO}_{4}$. The study is aimed at finding the extent to which metals corrode in the three most widely used industrial and laboratory acidic environments.

\section{EXPERIMENTAL DETAILS}

\section{Materials Used}

The following materials, chemicals, and apparatus were used for the research: $400 \mathrm{~mL}$ beakers; $1000 \mathrm{~mL}$ volumetric flasks; sand paper; 0.5-3.0 M nitric acid $\left(\mathrm{HNO}_{3}\right)$, hydrochloric acid $(\mathrm{HCl})$, and sulfuric acid $\left(\mathrm{H}_{2} \mathrm{SO}_{4}\right)$ solutions prepared from analytical grade reagents; distilled water; analytical weighing balance; tissue paper and clean cloth; analytical grade acetone reagent; and copper, galvanized iron, brass, zinc specimens were obtained from and cut into shape (pieces of equal sizes) at the metal market along Jimeta bye-pass.

\section{Method}

The metal specimens were first of all pretreated by polishing with sand paper, and cleaning with tissue paper and clean cloth. They were washed first with tap water, then distilled water, and finally washed with acetone in order to degrease them. The specimens were then completely air dried, and weighed on an analytical balance to four decimal places. The weights of the specimens were noted, and they were dipped into test solutions of $\mathrm{HCl}, \mathrm{HNO}_{3}$, and $\mathrm{H}_{2} \mathrm{SO}_{4}$. At 20 minutes interval (up to 100 minutes), the specimens were removed from the test solutions and first washed with tap water. This was followed by washing in distilled water, cleaning with fine cloth, washing again with distilled water, and further washing with acetone. The specimens were finally weighed on an analytical balance, and the differences in weights at each interval were noted.

The weight loss was calculated using the formula: W.L $=\left(W_{b}-W_{a}\right) / S$, where: $W_{b}$ and $W_{a}$ are the weights before and after immersion in $\mathrm{mg}$, and $\mathrm{S}$ is the total surface area of the specimen in $\mathrm{cm}^{2}$.

\section{RESULTS AND DISCUSSION \\ Corrosion Behavior and Mechanism of Copper}

The calculated weight loss of copper in four different concentrations each of $\mathrm{HCl}, \mathrm{HNO}_{3}$, and $\mathrm{H}_{2} \mathrm{SO}_{4}$ are plotted in figures 1-3. It could be observed that corrosion of copper takes place in all concentrations of $\mathrm{HCl}, \mathrm{HNO}_{3}$, and $^{\mathrm{H}_{2} \mathrm{SO}_{4} \text { due to }}$ considerable decrease in the specimen's original weight. Copper reacts slowly with $\mathrm{HCl}$ due to oxide layer formation on it [8]. Although as immersion time increases, copper begins to react with $\mathrm{HCl}$-first forming cuprous chloride and eventually cupric chloride as shown by the reaction equations below:

$$
\begin{gathered}
2 \mathrm{Cu}(\mathrm{s})+2 \mathrm{HCl}(\mathrm{aq}) \rightarrow 2 \mathrm{CuCl}(\mathrm{s})+\mathrm{H}_{2}(\mathrm{~g}) \\
\mathrm{Cu}(\mathrm{s})+2 \mathrm{HCl}(\mathrm{aq}) \rightarrow \mathrm{CuCl}_{2}(\mathrm{~s})
\end{gathered}
$$

Copper responds faster to concentration increase in $\mathrm{H}_{2} \mathrm{SO}_{4}$ than in $\mathrm{HCl}$ as it could be observed that $\mathrm{H}_{2} \mathrm{SO}_{4}$ corrodes copper at a faster rate than $\mathrm{HCl}$. This results from the difference in the oxidizing properties of the two inorganic acids, and the fact that $\mathrm{H}_{2} \mathrm{SO}_{4}$ has more strength than $\mathrm{HCl}$; therefore it has higher activity [8].

$\mathrm{HNO}_{3}$ has impacted the highest weight loss on the test specimen. This excessive corrosiveness of the acid solution is as a result of its powerful ability to readily oxidize materials, thereby violently attacking the surface of copper [1]. 


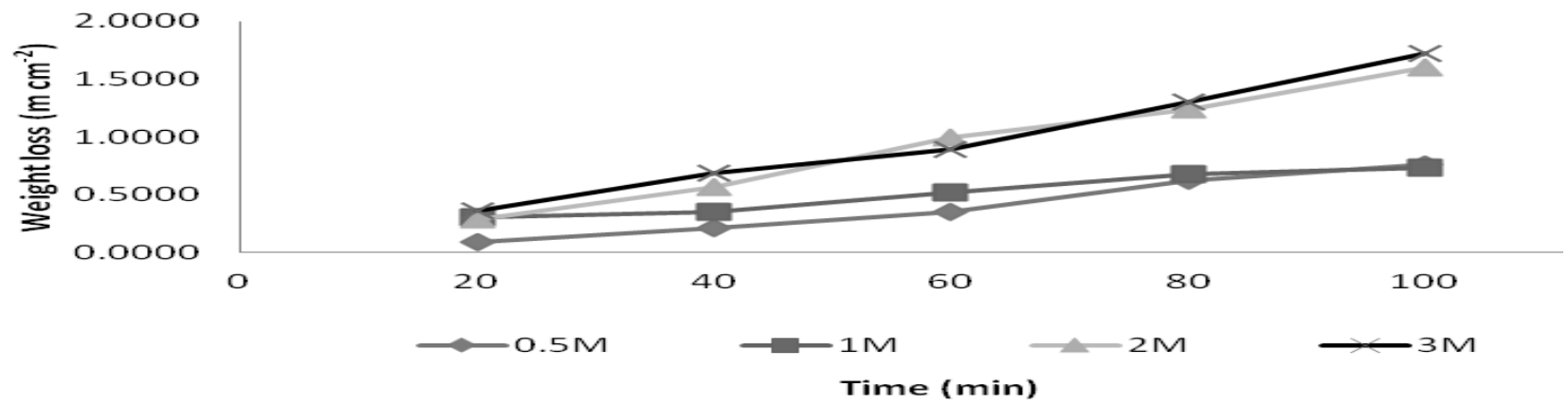

Figure 1: Weight Loss of copper in $\mathrm{HCl}$
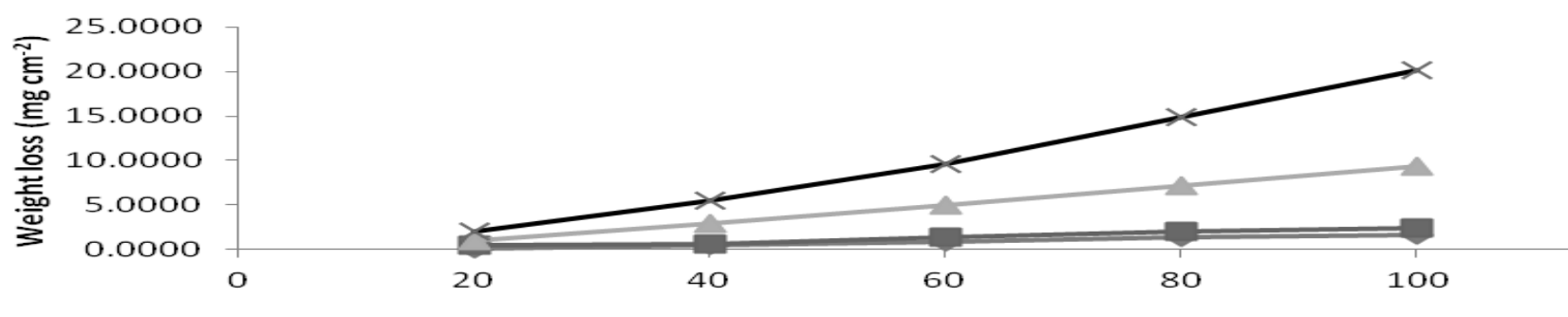

$\sim 0.5 \mathrm{M}$

$\longrightarrow-1 \mathrm{M}$

$-2 \mathrm{M}$

$3 \mathrm{M}$

Time (min)
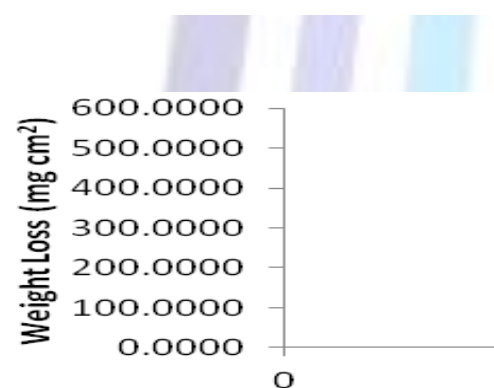

Figure 2: Weight Loss of copper in $\mathrm{H}_{2} \mathrm{SO}_{4}$

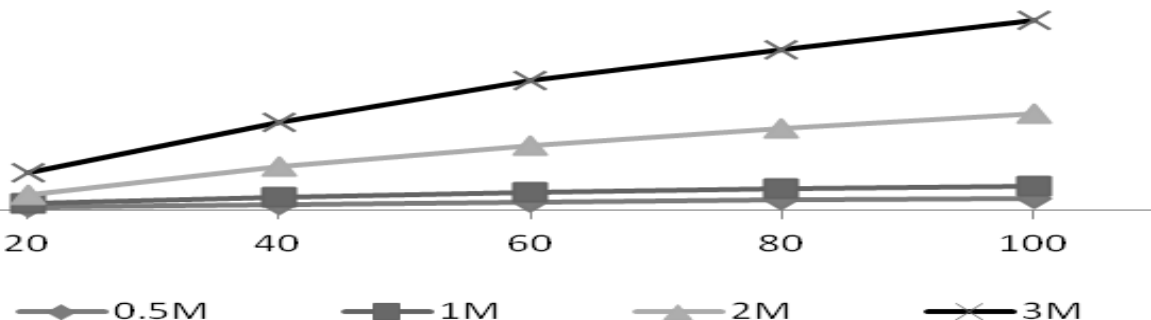

Time (min)

Figure 3: Weight Loss of copper in $\mathrm{HNO}_{3}$

\section{Corrosion Behavior and Mechanism of Galvanized Iron}

Figures 4-6 represent weight loss plots of galvanized iron in $\mathrm{HCl}, \mathrm{H}_{2} \mathrm{SO}_{4}$, and $\mathrm{HNO}_{3}$. The illustrations show that Increase in concentration increases weight loss per area of metal specimen. The weight loss also increases proportionally with increase in immersion time or period of time the metal is exposed to the acid solutions. $\mathrm{HNO}_{3}$ has proved to cause the most devastating corrosion or weight loss on galvanized iron similarly to what has been experienced in the case of copper.

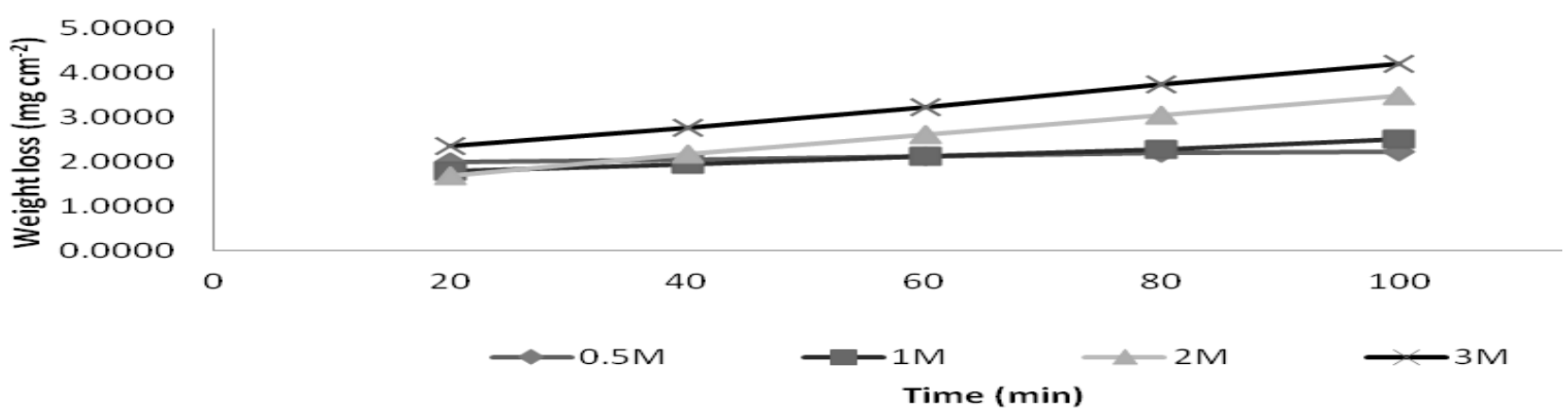

Figure 4: Weight Loss of Galvanized Iron in $\mathrm{HCl}$ 

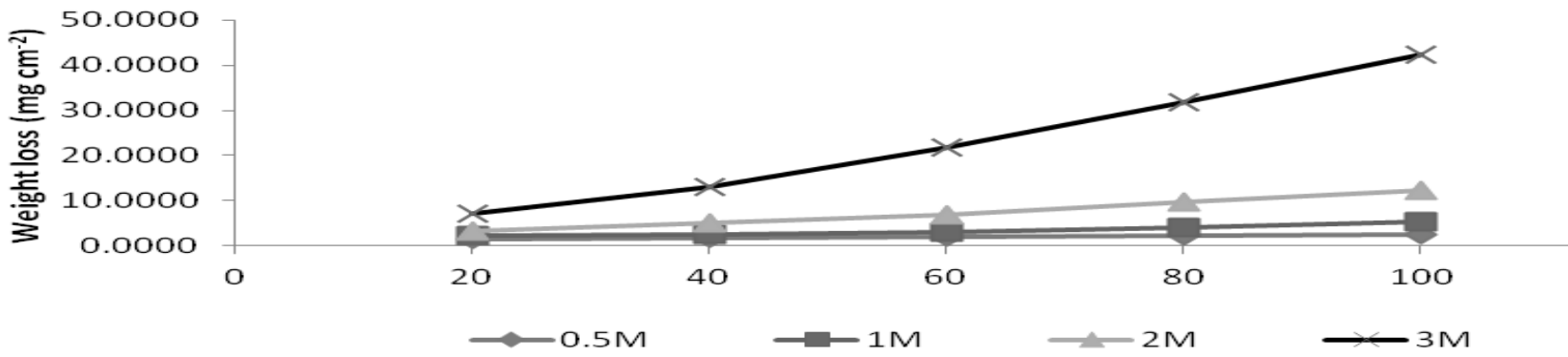

Time (min)

Figure 5: Weight Loss of Galvanized Iron in $\mathrm{H}_{2} \mathrm{SO}_{4}$
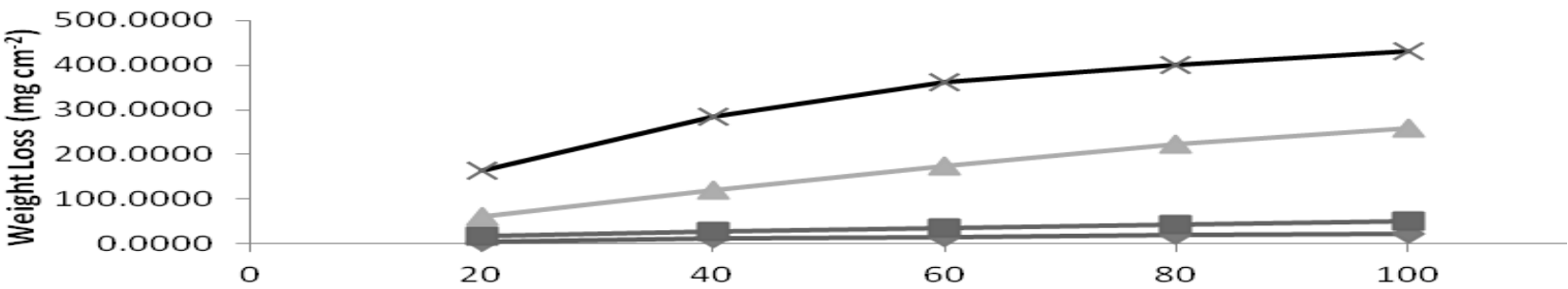

20

$\longrightarrow-1 \mathrm{M}$

$-2 \mathrm{M}$

$3 \mathrm{M}$

Time (min)

Figure 6: Weight Loss of Galvanized Iron in $\mathrm{HNO}_{3}$

\section{Corrosion Behavior and Mechanism of Zinc}

Weight plots for zinc corrosion are depicted in figures 7-9. Zinc corrosion in this medium followed the same corrosion pattern as that of already discussed metals. There was increase in metal corrodibility with increase in time and acid concentration. $\mathrm{HNO}_{3}$ 's enormous oxidizing ability was again exhibited in the corrosion of zinc as depicted in figure 9 . Strangely however; there is an incomplete result for zinc corrosion in $3.0 \mathrm{M}$ nitric acid because the metal specimen was on the verge of completely reacting with the acid after 60 minutes of exposure. Only tiny scattered pieces of it was discovered after the black-brownish colored reaction solution had been discarded. No further reaction was therefore carried out after 60 minutes, and result collection had ended after 40 minutes of exposure.

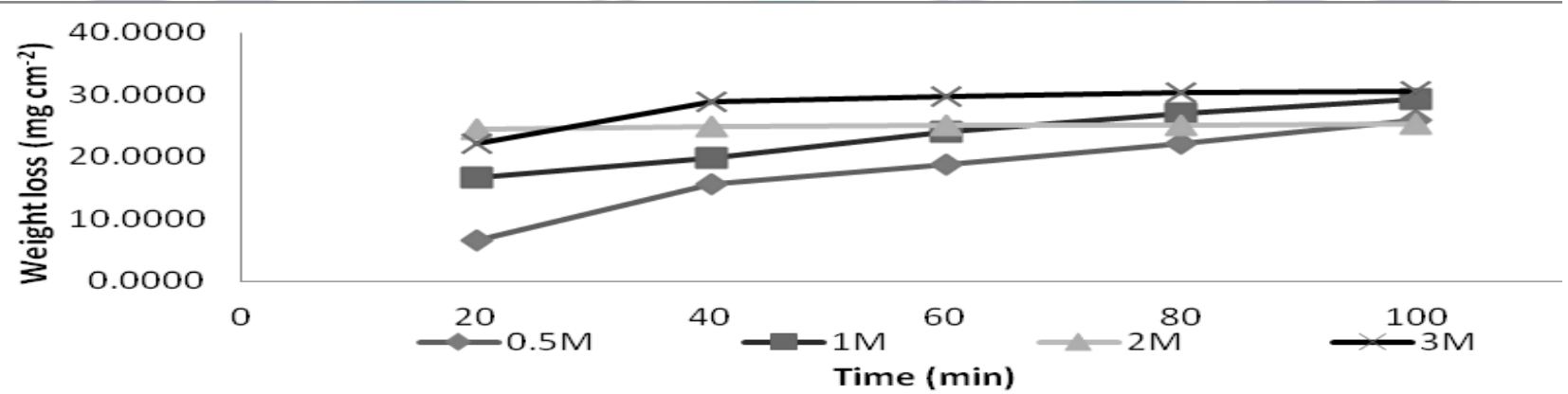

Figure 7: Weight Loss of Zinc in $\mathrm{HCl}$

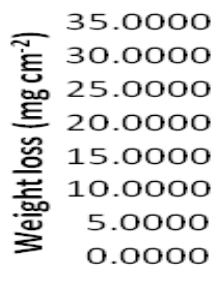

$-$

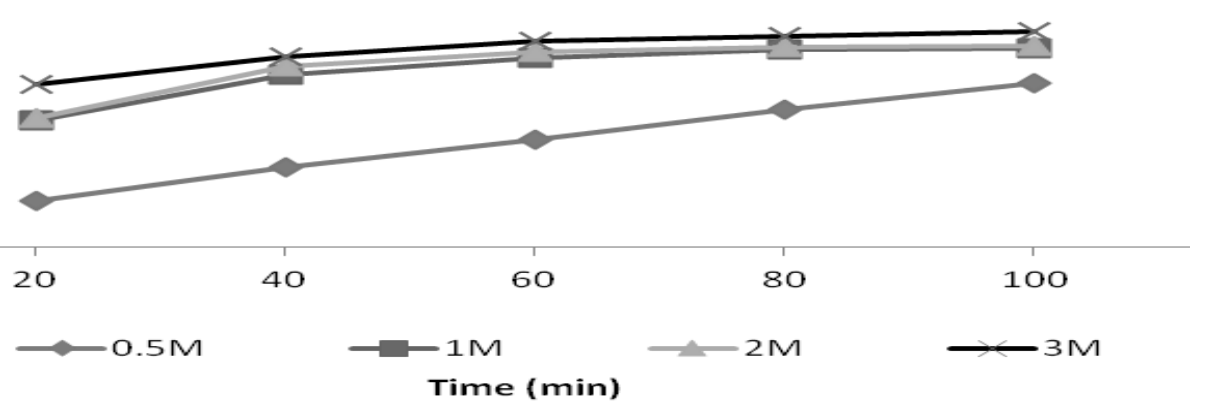

Figure 8: Weight Loss of Zinc in $\mathrm{H}_{2} \mathrm{SO}_{4}$ 


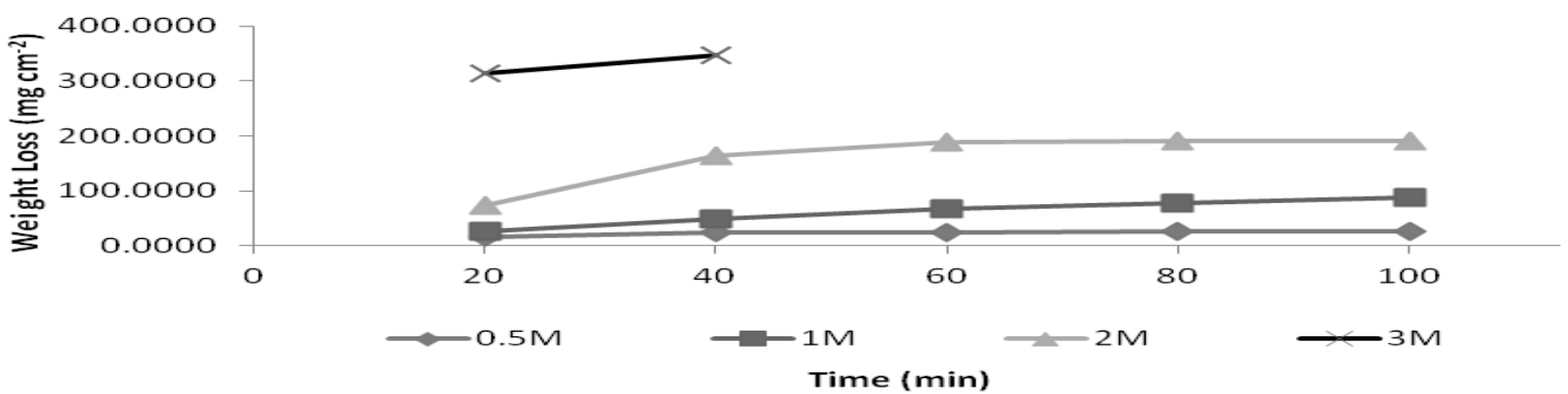

Figure 9: Weight Loss of Zinc in $\mathrm{HNO}_{3}$

\section{Kinetic Study}

The initial weight of the specimens and weight of specimens at various instants of time in all concentrations of the three acid media were used in calculating the specific reaction rate values, using first order rate expression; $\mathrm{k}=(2.303 / \mathrm{t}) \mathrm{Log}$ [(initial weight of specimen)/(weight at time, $t)]$. The half life time values were then calculated using the formula $t_{1 / 2}=$ $0.693 / \mathrm{k}$. Tables 1-9 illustrate these data.

It could be observed that the specific reaction rate, $\mathrm{k}$ increases as acid concentration increases. There is then a corresponding decrease in the half-life time values, thus confirming the first order kinetics for the corrosion of copper, galvanized iron, and zinc in all three solutions [1, 7]. In addition, it has been confirmed that $\mathrm{HNO}_{3}$ corrodes these metals the most because it has the highest $\mathrm{k}$ values, and the lowest half-life times at all concentrations. The specific reaction rates follow this order for the three acids used: $\mathrm{HNO}_{3}>\mathrm{H}_{2} \mathrm{SO}_{4}>\mathrm{HCl}$.

Table 1: Kinetics of the corrosion of copper in $\mathrm{HCl}$

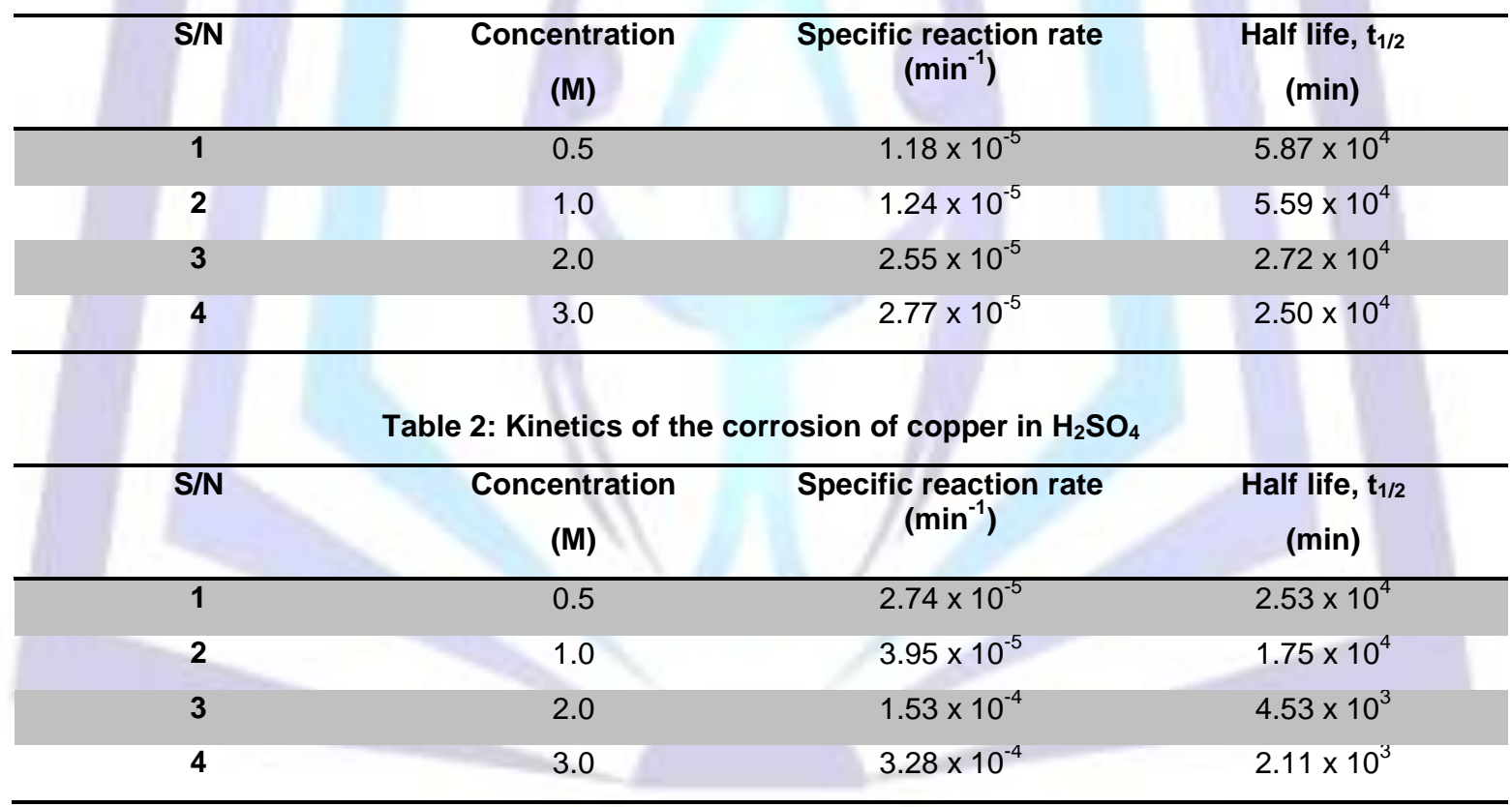

Table 3: Kinetics of the corrosion of copper in $\mathrm{HNO}_{3}$

\begin{tabular}{cccc}
\hline $\mathbf{S} / \mathbf{N}$ & $\begin{array}{c}\text { Concentration } \\
(\mathbf{M})\end{array}$ & $\begin{array}{c}\text { Specific reaction rate } \\
\left(\mathbf{m i n}^{-1}\right)\end{array}$ & $\begin{array}{c}\text { Half life, } \mathbf{t}_{\mathbf{1}} \mathbf{2} \\
(\mathbf{m i n})\end{array}$ \\
\hline $\mathbf{1}$ & 0.5 & $5.11 \times 10^{-4}$ & $1.36 \times 10^{3}$ \\
$\mathbf{2}$ & 1.0 & $1.06 \times 10^{-3}$ & $6.56 \times 10^{2}$ \\
$\mathbf{3}$ & 2.0 & $4.86 \times 10^{-3}$ & $1.43 \times 10^{2}$ \\
$\mathbf{4}$ & 3.0 & $1.44 \times 10^{-2}$ & $4.81 \times 10^{1}$ \\
\hline
\end{tabular}


Table 4: Kinetics of the corrosion of Galvanized Iron in $\mathrm{HCl}$

\begin{tabular}{cccc}
\hline $\mathbf{S} / \mathbf{N}$ & $\begin{array}{c}\text { Concentration } \\
(\mathbf{M})\end{array}$ & $\begin{array}{c}\text { Specific reaction rate } \\
\left(\mathbf{m i n}^{-1}\right)\end{array}$ & $\begin{array}{c}\text { Half life, } \mathbf{t}_{\mathbf{1}} \mathbf{2} \\
(\mathbf{m i n})\end{array}$ \\
\hline $\mathbf{1}$ & 0.5 & $1.98 \times 10^{-5}$ & $3.50 \times 10^{4}$ \\
$\mathbf{2}$ & 1.0 & $2.23 \times 10^{-5}$ & $3.11 \times 10^{4}$ \\
$\mathbf{3}$ & 2.0 & $3.17 \times 10^{-5}$ & $2.19 \times 10^{4}$ \\
$\mathbf{4}$ & 3.0 & $3.78 \times 10^{-5}$ & $1.83 \times 10^{4}$ \\
\hline
\end{tabular}

Table 5: Kinetics of the corrosion of Galvanized Iron in $\mathrm{H}_{2} \mathrm{SO}_{4}$

\begin{tabular}{cccc}
\hline $\mathbf{S} / \mathbf{N}$ & $\begin{array}{c}\text { Concentration } \\
(\mathbf{M})\end{array}$ & $\begin{array}{c}\text { Specific reaction rate } \\
\left(\mathbf{m i n}^{-1}\right)\end{array}$ & $\begin{array}{c}\text { Half life, } \mathbf{t}_{\mathbf{1}} \mathbf{2} \\
(\mathbf{m i n})\end{array}$ \\
\hline $\mathbf{1}$ & 0.5 & $2.27 \times 10^{-5}$ & $2.78 \times 10^{4}$ \\
$\mathbf{2}$ & 1.0 & $4.97 \times 10^{-5}$ & $1.39 \times 10^{4}$ \\
$\mathbf{3}$ & 2.0 & $1.11 \times 10^{-4}$ & $6.24 \times 10^{3}$ \\
$\mathbf{4}$ & 3.0 & $3.90 \times 10^{-4}$ & $1.78 \times 10^{3}$ \\
\hline
\end{tabular}

Table 6: Kinetics of the corrosion of Galvanized Iron in $\mathrm{HNO}_{3}$

\begin{tabular}{cccc}
\hline $\mathbf{S} / \mathbf{N}$ & $\begin{array}{c}\text { Concentration } \\
(\mathbf{M})\end{array}$ & $\begin{array}{c}\text { Specific reaction rate } \\
\left(\mathbf{m i n}^{-1}\right)\end{array}$ & $\begin{array}{c}\text { Half life, } \mathbf{t}_{\mathbf{1}} \mathbf{2} \\
(\mathbf{m i n})\end{array}$ \\
\hline $\mathbf{1}$ & 0.5 & $2.01 \times 10^{-4}$ & $3.45 \times 10^{3}$ \\
$\mathbf{3}$ & 1.0 & $4.51 \times 10^{-4}$ & $1.54 \times 10^{3}$ \\
$\mathbf{4}$ & 2.0 & $2.67 \times 10^{-3}$ & $2.60 \times 10^{2}$ \\
& 3.0 & $4.69 \times 10^{-3}$ & $1.48 \times 10^{2}$ \\
\hline $\mathbf{S} / \mathbf{N}$ & Table 7: Kinetics of the corrosion of Zinc in HCl & \\
\hline $\mathbf{1}$ & Concentration & Specific reaction rate & Half life, $\mathbf{t}_{\mathbf{1}} \mathbf{2}$ \\
$\left(\mathbf{m i n}^{-1}\right)$ & & \\
\hline $\mathbf{3}$ & $(\mathbf{M})$ & $7.09 \times 10^{-4}$ & $9.77 \times 10^{2}$ \\
$\mathbf{4}$ & 0.5 & $7.26 \times 10^{-4}$ & $9.55 \times 10^{2}$ \\
& 1.0 & $8.00 \times 10^{-4}$ & $8.66 \times 10^{2}$. \\
\hline
\end{tabular}

Table 8: Kinetics of the corrosion of Zinc in $\mathrm{H}_{2} \mathrm{SO}_{4}$

\begin{tabular}{cccc}
\hline $\mathbf{S} / \mathbf{N}$ & $\begin{array}{c}\text { Concentration } \\
(\mathbf{M})\end{array}$ & $\begin{array}{c}\text { Specific reaction rate } \\
\left(\mathbf{m i n}^{-1}\right)\end{array}$ & Half life, $\mathbf{t}_{\mathbf{1}} \mathbf{2}$ \\
\hline $\mathbf{1}$ & 0.5 & $7.16 \times 10^{-4}$ & $9.68 \times 10^{2}$ \\
$\mathbf{2}$ & 1.0 & $8.06 \times 10^{-4}$ & $8.60 \times 10^{2}$ \\
$\mathbf{3}$ & 2.0 & $8.21 \times 10^{-4}$ & $8.44 \times 10^{2}$ \\
$\mathbf{4}$ & 3.0 & $8.48 \times 10^{-4}$ & $8.17 \times 10^{2}$ \\
\hline
\end{tabular}


Table 9: Kinetics of the corrosion of Zinc in $\mathrm{HNO}_{3}$

\begin{tabular}{cccc}
\hline $\mathbf{S} / \mathbf{N}$ & $\begin{array}{c}\text { Concentration } \\
(\mathbf{M})\end{array}$ & $\begin{array}{c}\text { Specific reaction rate } \\
\left(\mathbf{m i n}^{-1}\right)\end{array}$ & Half life, $\mathbf{t}_{\mathbf{1}}$ \\
\hline $\mathbf{1}$ & 0.5 & $9.46 \times 10^{-4}$ & $7.33 \times 10^{2}$ \\
$\mathbf{2}$ & 1.0 & $2.54 \times 10^{-3}$ & $2.73 \times 10^{2}$ \\
$\mathbf{3}$ & 2.0 & $6.83 \times 10^{-3}$ & $1.01 \times 10^{2}$ \\
$\mathbf{4}$ & 3.0 & - & - \\
\hline
\end{tabular}

\section{CONCLUSION}

The corrosion behavior and mechanism of copper, galvanized iron, zinc, and brass have been studied under different media by weight loss method. Four different concentrations viz $0.5 \mathrm{M}, 1 \mathrm{M}, 2 \mathrm{M}, 3 \mathrm{M}$, were used for different timings viz 20100 minutes. From the research study, the following conclusions have been arrived at.

- Metals are highly corroded in acid solutions.

- Corrosion rate or weight loss increases with increasing acid concentration and decreases with increasing time of exposure.

- The order of corrosion activity under the different acid media has been found to be: $\mathrm{HNO}_{3}>\mathrm{H}_{2} \mathrm{SO}_{4}>\mathrm{HCl}$.

- The order of reactivity on the metals has been found to be: Zinc > Galvanized iron > Copper.

- Rate of corrosion reaction (specific reaction rate) of metals increases with a first order degree as acid concentration increases. The half life time on the other hand decreases with an increase in concentration.

\section{REFERENCES}

[1] Patil, D. B. \& Sharma, A. R. 2011. Study on the Corrosion Kinetics of Iron in Acid and Base Medium. E-Journal of Chemistry 8, 358-362.

[2] Samina, M., Abdul-Karim, and Venkatachalam, A. 2011. Corrosion Study of Iron and Copper Metals and Brass Alloy in Different Medium. E-Journal of Chemistry 8, 344-348.

[3] Ajide, O. O. \& Agara, K. W. 2012. Comparative Study of Corrosion Characteristics of MCS and KS7 SS in Selected Acid Media. Int. J. of Metallurgical Eng. 1, 7-11.

[4] Abdulmaruf, S. \& Dajab, D. D. 2007. Corrosion Behavior of Copper Immersed in Different Environment. Zaria Capter Book of Proceedings 3, 67-70.

[5] Kumar, A., Shukla, R., Venkatachalam, A. 2013. Studies of Corrosion and Electrochemical Behavior of Some Metals and Brass Alloy under Different Media. Rasayan J. Chem. 6, 12-14.

[6] Ikpesu, J.E. 2014. Investigation of Weight Loss and Corrosion Rate of Bi-metals and Tri-metal in Acidic Environment. J. of Res. in Env. Sci. and Toxicology 3, 15-20.

[7] Noor, E. A. \& al-Moubaraki, A. H. 2008. Corrosion Behavior of Mild Steel in Hydrochloric Acid Solutions. Int. J. of Electrochem. Sci. 3, 806-818.

[8] Choudhary, G., Sharma, A., Sharma, A. 2013. Corrosive Behavior of Al, Cu and MS in Different Acidic Media. Int. J. of Innovative Res. in Sci. Eng. and Tech. 2, 5467-5479. 